\title{
The effectiveness of group counseling based on problem- solving solution on sexual function and sexual satisfaction of women after mastectomy surgery
}

\section{Mahshid Bokaie}

Shahid Sadoughi University of Medical Sciences

Ommolbanin Firouzabadi ( $\nabla$ firoozabadi@farabi.tums.ac.ir)

MA, Shahid Sadoughi University of Medical Sciences

\section{Azadeh Joulaee}

Mahdieh University Women's Hospital, Shahid Beheshti University of Medical Sciences

\section{Research Article}

Keywords: Breast cancer, mastectomy, Sexual Dysfunction psychological, sexual satisfaction, problemsolving, women

Posted Date: March 23rd, 2021

DOl: https://doi.org/10.21203/rs.3.rs-296351/v1

License: (9) (i) This work is licensed under a Creative Commons Attribution 4.0 International License. Read Full License 


\section{Abstract}

Background: Breast cancer is the second cause of death due to cancers and it is the most common cancer in women, which threatens different aspects of individual and mental health, quality of life, sexual function and sexual satisfaction, because of such treatments as mastectomy. Consultation can help patients to and a reasonable solution for their problems. Considering the effect of consultation on quality and quantity of patients' life and the importance of the role of midwife in sexual health consultation, this research is carried out in order to determine the effect of group consultation based on problem-solving solution on sexual function and satisfaction of women who have had mastectomy surgery.

Method: The present research is a semi-empirical study, with pretest, post-test and

one month follow-up period. 32 women who referred to Tehran Breast Cancer Institute were selected by convenience sampling.The group received 8 sessions (90-minute) of problem-solving solution conselling. The data collection tool was Female Sexual function Index and Larson sexual satisfaction questionnaires and filled before intervention, immediately after intervention and one month after it.

Data analysis was performed by using SPPSS21 statistical software application at the certainty level of 95\% (Ps0.05).

Results: The results of the study showed that there is a meaningful difference between the average sexual function $(18.37,20.88,22.95)$ and the sexual satisfaction $(65.27,68.08,70.46)$ in three stages before the intervention, immediately after the intervention and one month after the intervention.

Conclusions: Although the average score of women's sexual performance and the average score of sexual function of women who had mastectomy operation have improved, and this change was significant, but we have to note that the sexual function and sexual satisfaction are still in an inappropriate situation which require the continued trend of counseling in these patients. Considering the fact that the outbreak of breast cancer is very high, counseling can transfer to patients the information that is necessary for creating a desirable sexual life. In addition, through counseling process, we can teach patients how to live with their disease.

\section{Background}

Breast cancer constitutes almost one-fourth of all cancers in women (1) and it is the most common cancer among them. One out of eight women is suffering from breast cancer, to which almost 1.5 million women are afflicted each year. Moreover, breast cancer stands at the top of the list of mortality caused by cancer among women. In 2015, 570,000 women died because of breast cancer and this type of cancer is the second cause of mortality due to cancers (2). Incidence of breast cancer in Iran is reported as 31 per 100,000 women, and the most age group pertains to $42-49$ years old (3). Breast cancer is the most mortal neoplasia among women, both from physical and mental points of view (4). In most of societies and cultures, this organ is considered a female organ, and because of its importance in forming the female identity, reaction to the disease can include fear, anxiety and depression. For this reason, losing this organ 
is mostly interpreted as losing the female identity. Some of the new causes of these problems will create implicit meanings of this diagnosis in patient's mind including the likelihood of body deformation, pain, lack of financial and social support, losing female identity and sexual desire, reduced social activity, concern about ambiguous future, recurrence of disease, death, etc (5). After occurrence of breast cancer in women, breast surgery is performed in two methods: conserving the breast (removing the breast tumor together with the surrounding healthy texture) and mastectomy, i.e. complete removal of breast. Mastectomy surgery will completely destroy the body image of patients and will have a deep impact on spiritual status of patients (6).

Sexual dysfunction is defined as desire disorder, stimulation, orgasm and sexual pain (7). Sexual dysfunction in women means permanent and recurrent disorder in four areas of sexual desire, sexual response, sexual intercourse pain or inability in achieving maximum sexual joy (8). Such factors as mental health, sexual relation, sexual function of the sexual partner, factors associated to the person's personality, infertility, medicines, chronic diseases, women hip surgeries, gynecological diseases and malignancies, pregnancy diabetes and post-delivery period are effective in occurrence of sexual dysfunctions (9). Sexual changes affecting the sexual function including fatigue, painful intercourse, vaginal tightness, absence of or reduced sexual desire and breast numbness are created following a breast cancer and its treatment (10). Sexual dysfunction after breast cancer possibly remains more than one year after diagnosis of the disease. It seems chemotherapy is the cause of all sexual problems such as reduced sexual desire and mental arousal, vaginal dryness and dyspareunia (11). As the most common treatment procedure, Mastectomy has a direct impact on sexual function of women with breast cancer, while in BreastConserving Surgery, it does not have a direct impact on sexual activity, besides it has a positive impact on sexual function, by creating a positive imagination of body (12).

Sexual satisfaction is a multilateral concept, including both emotional and physiological aspects of sexual intercourse. Sexual satisfaction is not only the physical joy, and it includes all remaining emotions after positive and negative aspects of sexual intercourse (13). Providing counseling services for patients will reduce their tension, so that they will consider others' direction and assistance vital for compatibility with their emotions (14). Group Counseling, is a bilateral process, in which the counselor and an identical group will study the problems and approaches. In group counseling members show a large degree of reaction towards each other and this issue will increase insight acquisition. Counseling programs, used to improve the level of sexual function and satisfaction, will increase sexual function and sexual satisfaction (15).

Educating the problem-solving issue mentions a cognitive-behavioral process, that provides a variety of alternative and potential responses for controlling the problematic conditions and increases the possibility of choosing best and most effective alternative responses. Advantage of problem-solving method is that we can use it for individual and/or group treatments (16). This type of treatment will initiate an active cooperation between the patient and the therapist (17). Through a study, Otto et al. showed that education of problem-solving skills has a positive influence on approach of patients with cancer (18). Gaskell et al. believed that for improving midwives' capability in advanced clinical skills, innovation in problem-solving 
services and skills require training, thus strengthening the problem-solving skills will be also effective in improvement of cares (19).

Considering the high outbreak of breast cancer, a counselor can convey to patients the information required for establishing a desirable sexual life. In Iran, breast cancer is mostly observed in young women, who are in their active age of family, sexual and social life and the evidences show a widespread and vast sexual disorders in women who have had mastectomy surgery. Destructive effect of breast removal on one hand and not receiving sexual counseling services on the other hand reveal the necessity for evaluation and paying attention to the factors mentioned in these patients. The present study was thus performed with the goal of analyzing the effect of group counseling on sexual function and sexual satisfaction of women who had mastectomy surgery in Tehran Breast Cancer Institute.

\section{Method}

\section{Study design}

The present research is a semi-empirical study, with pretest, post-test and one month follow-up period. Written informed consent were obtained from all participants.

\section{Participants}

Forty of the patients referring to Tehran Breast Cancer Institute in 2020 were invited to participate in the study and 32 persons were studied considering the inclusion and exclusion criteria.

\section{Inclusion criteria}

I. Cancer stages between I to III

II. 1 to 5 years after breast surgery

III. Iranian nationality

IV. Resident in Tehran/IRAN city

V. 30-59 years old women

VI. Ability to read and write

VII. Mastectomy

VIII. Married

IX. Single partner

$X$. Do not participating in any other consulting class

XI. finished chemotherapy

\section{Exclusion criteria}

I. lumpectomy surgery 
II. recurrent cancer

III. Taking drugs that affect sexual function

IV. Suffering from chronic diseases

V. Being pregnant

VI. Recurrent cancer

VII. Alcohol and drug addiction by self-report

VIII. Participating in supportive groups

\section{Dropping criteria}

- Absence in more than 2 sessions

- Immigration

- failure to do more than $30 \%$ of homework

- Occur stressful events such as death of relatives, divorce

\section{Instruments}

Research instruments include demographic characteristics questionnaire, Female Sexual Function Index (FSFI) questionnaire, and Larson sexual satisfaction questionnaire. Demographic characteristics questionnaire include age, education, marital stats, pregnancy prevention method, breast cancer grading, performing or not performing surgery, chemotherapy and radiotherapy records.

Female Sexual Function Index (FSFI): includes 19 questions, each with 4 answer options. This standard questionnaire measures 6 dimensions of sexual function (sexual desire, orgasm, stimulation, sexual pain, lubrication and sexual satisfaction) over the recent 4 weeks. Measures were exactly taken as per the questionnaire in order to determine the score of each person in each section and also to determine the general score. The score of each section was obtained by adding the scores of questions related to the same section and multiplying the sum-up in coefficient of each section. The sexual desire disorder is the score below 4.28, sexual response disorder is the score below 5.08 , lubricious disorder is the score below 5.45 and orgasm disorder is the score below 5.05, and sexual satisfaction disorder is the score below 5.04 . The cutting point for determining the sexual disorders is the score 28 or less. So that the persons whose total score of sexual function is 28 or less, have sexual function disorder. The total point obtained is calculated in different areas. It is obvious that the total score is obtained through adding up of 6 sections. The reliability degree of scale and micro-scales was obtained through calculating the Cronbach's alpha coefficient, which was calculated $70 \%$ and higher for all persons, indicating the good reliability of this instrument (20).

Larson Sexual Satisfaction Standard Questionnaire: This questionnaire consists of 25 5-answer choice questions, and it is based on a Likert scale from one to five, and the "never" choice receives score 1 , "rarely" choice receives score 2, "sometimes" choice receives score 3, "most of the times" choice receives score 4 and "always" choice receives score 5 . Total score of 25-75 is equal to low sexual satisfaction, 76100 is equal to medium sexual satisfaction and score $101-125$ is equal to high sexual satisfaction. In his 
thesis titled "study of relation of sexual satisfaction with individual factors in couples", Rahmani (2008) also used this questionnaire and used the re-test method in order to determine the reliability of instruments and he achieved $r=86 \%(21)$.

After phone calls, written letter of consent was received from all research units and assurance was given to them that the study results are confidential and they will be published without names mentioned and they can leave the research at any stage.

Intervention: Counseling program based on problem-solving approach including 890 -minute counseling sessions once a week were designed for the participants based on a review of texts and research team's opinion. In this research, teaching the problem-solving was designed based on Dezorella and gold Fried problem-solving phases. Teaching the problem-solving five-fold skills was presented in a session by researcher in the form of speech, questions and answers, group discussion and slide presentation. Decision of authorities for solving their own problem, taught after the counseling and problem-solving in this study, was an important confrontational strategy, that increased ability and personal-social progress and reduced mental tension and symptoms. Studied groups were formed in 4 groups, each consisting of 8 persons in a suitable location in breast cancer institute. A summary of contents of the sessions is outlined in Table 1. 


\section{Sessions Subjects of Discussion}

One Introduction, anatomy and physiology of reproductive system, sexual cycle, female sexual organ and erogenous zones and factors affecting them, explanation on how to fill in questionnaire, presenting homework

Two Importance of sexual relation and lack of concentration on penetration in all sexual relations of the couple, speaking on cancer and its effects, treatments and its complications, homework and how couple get along with this problem, giving homework,

Three $\quad$ Training the problem-solving skills, confronting with stress, techniques of relaxation and establishing effective communication, exchange of views regarding alternative solutions for improving couple's relation in breast cancer, giving homework

Four Review of sexual schemas and women's concerns and their control, review of their sexual expectations, training of sexual skills, sensational exercises, necessary readiness for relation, explanation regarding home assignments such as common massage, and giving home assignments

Five $\quad$ Free discussion regarding the issues and problems, defining exact conformation of issue, generating solution and determining a range of possible solutions, analyzing the solutions, problems created following execution of individual solutions, weaknesses and strengths of individual solutions and anticipating the consequences, development and strengthening communication skills, managing negative excitement (negative anger and excitement), and training relaxation, responding to questions, giving home assignments

Six Suitable solutions against complications caused by cancer in sexual matters, changes in appearance, communication techniques, reducing worries through counseling, introduction to Kegel exercise and other effective factors in strengthening the sexual function (nutrition, concentration on moments of enjoying it, etc.) responding to questions, giving home assignments

Seven Review of previous sessions and implementation of solution for real cases that have been set forth

Eight Presence of spouses and study of their sexual expectations and taking about sexual and mental differences of men and women in each stage of sexual cycle, sexual interactions, sexual response and solutions to improve sexual satisfaction, explaining on how to fill in questionnaire

The questionnaires were completed by participants before the study, immediately after it and one month after the study. After data codification and data input into SPSS21 software, by use of descriptive statistics methods and in order to analyze data in case of normal distribution of data, parametric tests such as variance analysis with repeated observations and Bonferroni post hoc test were performed at the certainty level of $95 \%(P \leq 0.05)$.

\section{Results}

This study was performed on 32 women who had mastectomy surgery who referred to Tehran Breast Cancer Institute in 2020 with convenience sampling method. The average age of women in this research 
was $39.81 \pm 7.54$, spouse's age of $43.81 \pm 8.67$, marriage duration were $14.9 \pm 81.59$, cancer affliction period of $4.69 \pm 3.08$, and post-treatment time interval of $3.47 \pm 3.12$. All participants had been experienced chemotherapy and 27 persons (84.4\%) had been experienced radiotherapy. Some of the demographic characteristics of research samples are mentioned in Table 2.

Table 2

Patients' Demographic Characteristics

\begin{tabular}{|llll|}
\hline Variable & & Number & percentage \\
\hline Level of women education & Under diploma & 6 & 18.8 \\
& Diploma & 11 & 34.4 \\
& University degrees & 15 & 46.8 \\
\hline Level of husband education & Under diploma & 6 & 18.8 \\
& Diploma & 11 & 34.4 \\
Women's Job & University degrees & 15 & 46.8 \\
\hline Husband's Job & Housewife & 20 & 62.5 \\
& Employed & 12 & 37.5 \\
& Employee & 10 & 31.2 \\
& Self-employed & 3 & 9.4 \\
Contraception method & Laborer & 19 & 59.4 \\
& Hormonal & 3 & 9.4 \\
& IUD & 7 & 21.8 \\
& Withdrawal & 18 & 56.3 \\
& TL & 4 & 12.5 \\
\hline Cancer grading & I & 6 & 18.8 \\
& II & 21 & 65.6 \\
& III & 12.5 \\
\hline
\end{tabular}

Mean score of sexual satisfaction before intervention, immediately after intervention and one month after intervention were obtained $65.27 \pm 5.98,68.08 \pm 5.61$ and $70.46 \pm 5.35$ respectively. The statistical test shows a significant difference in 3 stages $(P<0.05)$ (Table 3$)$. 
Table 3

Comparing the Criterion Average and Deviation of Sexual

Satisfaction in Three Periods

\begin{tabular}{|lll|}
\hline Time & Average & Standard deviation \\
\hline before intervention & 65.27 & 5.98 \\
\hline immediately after intervention & 68.08 & 5.61 \\
\hline one month after intervention & 70.46 & 5.35 \\
\hline
\end{tabular}

Also according to the results, average and deviation of criterion resulted for six-fold dimensions of sexual function was achieved as $2.0 \pm 98.67$ with sexual desire, $2.98 \pm 1.30$ with sexual stimulation, $2.91 \pm 1.47$ with lubrication, $3.24 \pm 1.78$ with orgasm, $3.1 \pm 39.67$ with sexual satisfaction, and $3.2 \pm 18.08$ with intercourse pain. Based on the percentages mentioned above, the highest degree of disorder pertains to lubrication and its lowest degree pertains to satisfaction (Table 4). Based on variance analysis test, with repeated observations there was a direct and significant relation among all aspects of sexual function in three times.

Table 4

Comparing the Criterion Average and Deviation of Total Score of Sexual Function and its Dimensions

\begin{tabular}{|c|c|c|c|c|c|c|c|c|}
\hline \multirow{2}{*}{$\begin{array}{l}\text { dimensions } \\
\text { of sexual } \\
\text { function }\end{array}$} & \multicolumn{2}{|c|}{ before intervention } & \multicolumn{2}{|c|}{$\begin{array}{l}\text { immediately after } \\
\text { intervention }\end{array}$} & \multicolumn{2}{|c|}{$\begin{array}{l}\text { one month after } \\
\text { intervention }\end{array}$} & \multirow[t]{2}{*}{$\mathbf{F}$} & \multirow[t]{2}{*}{$\mathbf{P}$} \\
\hline & Average & $\begin{array}{l}\text { Standard } \\
\text { deviation }\end{array}$ & Average & $\begin{array}{l}\text { Standard } \\
\text { deviation }\end{array}$ & Average & $\begin{array}{l}\text { Standard } \\
\text { deviation }\end{array}$ & & \\
\hline Total score & 18.37 & 8.35 & 20.88 & 7.67 & 22.95 & 5.79 & 20.53 & $\dot{c}_{0.001}$ \\
\hline $\begin{array}{l}\text { Desire } \\
\text { sexual }\end{array}$ & 2.98 & 0.67 & 2.99 & 0.68 & 3.11 & 0.71 & 15.96 & $\dot{c}_{0.001}$ \\
\hline $\begin{array}{l}\text { Motivation } \\
\text { sexual }\end{array}$ & 2.98 & 1.30 & 3.22 & 1.04 & 4.43 & 0.98 & 6.98 & 0.003 \\
\hline Lubrication & 2.91 & 1.47 & 3.36 & 1.32 & 4.02 & 0.99 & 24.02 & <. 001 \\
\hline orgasm & 3.24 & 1.78 & 3.81 & 1.36 & 4.08 & 0.96 & 10.39 & 0.001 \\
\hline Satisfaction & 3.39 & 1.67 & 3.9 & 1.54 & 4.07 & 1.02 & 11.63 & $\begin{array}{l}<.001 \\
0.001\end{array}$ \\
\hline Pain & 3.18 & 2.08 & 3.60 & 1.73 & 3.24 & 1.14 & 10.51 & 0.001 \\
\hline
\end{tabular}

\section{Discussion}


Breast cancer is the most common cancer in women, threatening various aspects of personal and mental health, life quality, sexual function and sexual satisfaction, because of such complications as mastectomy. Considering the importance of sexual function and sexual satisfaction and its effect on quality of life, the present study is conducted with the goal of studying the effect of group counseling on sexual function and sexual satisfaction of women who had mastectomy surgery. $40 \%$ of patients afflicted to breast cancer, suffer sexual dysfunction upon commencement of treatment and $50 \%$ of women who are afflicted to breast cancer experience these disorders in long time. Usually the treatment team focus on preserving and continuing patient's life and less attention is paid to patients' sexual function. Depression and stress after diagnosis of breast cancer, side effects of chemotherapy medicines during treatment, and disorder of mental image of the body after mastectomy are all causes of sexual dysfunction (22). Significant difference was created in all 6-fold areas of sexual function and those tested achieved higher grades in each phase and this shows that counseling has improved their sexual function. In a study conducted by Rostamkhani et al. in the stages of two weeks and four weeks after counseling, significant difference was observed between the average score of sexual function in the two intervention and observation group. Also in the intervention group, significant difference was created between the average scores of the areas of sexual desire, sexual arousal, wetness during sexual intercourse, orgasm, sexual satisfaction and pain before and after counseling, and the scores after counseling had significantly increased (23). Results of the study performed by Heravi Karimoi et al. who identified the effect of group counseling on quality of sexual life in those who suffer from cancer, showed that group counseling will improve the scales of body image, sexual function and sexual enjoyment and the quality of sexual life of afflicted individuals have improved as a result of group counseling (24). In the present study, $21.9 \%$ of individuals suffered from sexual function disorder. There was $93.8 \%$ improvement in sexual function before intervention compared to the function one month after the intervention (based on total numbers of questionnaires in three time intervals per individual persons). Highest degree of disorder was related to sexual desire and the lowest degree was related to sexual stimulation. This disorder can be resulted from stress, diagnosis and treatment of breast cancer or complications of chemotherapy and surgery operation. In a study conducted by Kedde and et al (2013) in the Netherlands, women who had afflicted to breast cancer in the past 6 years and who were younger than 45 years old, participated in this study. Considering all disorders studied in women of Netherlands' population, breast cancer was more common among young women. $64 \%$ of women who were still under breast cancer treatment, had sexual dysfunction and this disorder was $45 \%$ for those women whose treatment was over and they were no longer under treatment. Hormone therapy resulted in permanent genital arousal disorders (PGAD), radical mastectomy resulted in long disorder of female orgasm and painful intercourse and in beginning of menopause half of the women reported that the issue of "changes in sexual function" was observed during treatment. Results showed that sexual disorders among young women who suffered from breast cancer are mostly common and sexual counseling sessions were advised in these people in order to improve the sexual function (25). Results of the study conducted by Wang et al (2013), showed that decreased frequency of sexual relation, sexual unwillingness, menopause symptoms, change in body image, effect on matrimonial relations and wrong imaginations and conceptions regarding the sexual relations were shown (26). In a study conducted by Reese et al. (2020), in order to evaluate an intervention based on couple in addressing the sexual 
concerns for survivors of breast cancer, 120 couples were studied. This study evaluated the efficiency of a four-session intervention for the couple, carried out via telephone as increasing intimacy. The intervention was performed with full concentration on matrimonial relation and full participation of sexual partners in targeted activities and it improved the matrimonial skills for confronting with sexual issues and increasing intimacy. Using telephone had much more advantages compared to face-to-face methods and based on network. This method was evaluated to be much more appropriate for studies after treatment. Results of the study showed that sexual concerns for breast cancer survivors are not mostly removed and evidencebased interventions are necessary, particularly in those cases that the survivors have partners (27). Thus breast cancer and its normal treatments create disorder in sexual function. This group of patients are afflicted to early menopause, and as a result reduced estrogen will cause vaginal atrophy and reduced androgen will cause reduced sexual desire and arousal.

In the studies carried out in different countries, it has been repeatedly stated that women feel their sexual function is affected by mastectomy $(28,29)$. Fobair et la. Showed that sexual function problems and the mental image of the body, are the common problems of patients with breast cancer (30). In this study, before intervention $90.6 \%$ of persons had low sexual satisfaction and $9.4 \%$ had good sexual satisfaction. This is while one month after the intervention, $84.4 \%$ of the units subject of research had low sexual satisfaction and $12.5 \%$ had good sexual satisfaction, and this was the highest degree of sexual satisfaction in three time periods.

In a study performed by Vardanjani et al (2013), mastectomy surgery in comparison with lumpectomy had noticeable influence on sexual satisfaction of couples and after mastectomy, people suffered from sexual dysfunction (31).

Group counseling is a bilateral process, in which the counselor and a similar group study problems and concerns. In group counseling, members show more reaction to each other and this issue will lead to obtaining insight. Counseling programs, used to improve level of sexual performance and satisfaction, will increase sexual function and sexual satisfaction (15).

Through counseling process, we can teach patients who suffer from cancer, how to live with their disease. As a dynamic process for solving the problem, a counselor can improve the quality of sexual life and significantly reduce stress, increase knowledge, knowledge and strengthen the personal perception of the life targets and improve the patient's compatibility and capability compliance behaviors(32).

Due to high outbreak and importance of sexual problems and absence of necessary and adequate trainings, group therapy sessions are recommended to be considered for the couples. Problem-solving skills to be trained for women with cancer, beside other therapies, and planning for training psychocognitive intervention, specially the problem-solving skill for patients with breast cancer to be carried out.

\section{Study Limitations}

Among the limitations of this research, we can mention: having no access to patients with breast cancer record, who were not member of the Center, holding no classes for the husbands of these women, because 
the main focus of this study was on the patients themselves, carrying out study on husbands as care giver will increase participation and boost their motivation, which results in more influence on patients, limited number of studies carried out in the area of specifying the effect of group counseling with the approach of problem solving on sexual function and sexual satisfaction of women who had mastectomy surgery in Iran. Considering the limitations and considerations that this group of recovered patients have, and due to the fact that doing a research in a metropolitan city like Tehran, has many transportation problems, it is recommended that for carrying out group therapy sessions, some centers or institutes to be used.

\section{Conclusion}

Considering the results of the present research, that showed the effect of midwifery counseling in improvement of sexual function and sexual satisfaction of patients who had breast cancer, we can say that counseling can convey to the patients, the information that is required for establishing a desirable sexual life and performing group counseling in women with mastectomy surgery affects and improves their sexual function and sexual satisfaction.

\section{Abbreviations}

FSFI: Female Sexual Function Index

\section{Declarations}

\section{Ethics Approval and Consent to Participate}

We were followed national guidelines in the ethical approval and informed consent. First we achieved college proposal approval; Then we achieved national ethical and informed consent approval (code: IR.SSU.MEDICINE.REC.1397.176). During telephone calls, the researcher introduced herself and explained the research targets and in case people showed interest to participate in research, adequate explanations were given to them regarding the confidentiality of information and nondisclosure of their names. In the next step, the units subject of research were invited in order to give written letters of consent and complete the questionnaire. A counseling-training session was also held for husbands of the units subject of research.

\section{Written letters of consent}

You are hereby invited to participate in the above research. Hereby, we are providing you with information about this research. You can choose to participate if you are willing.

You do not have to make an immediate decision. You can ask your questions of the research team and consult with any expert you wish in order to make the decision. Before signing this consent form, make sure that you have sufficiently and properly understood all the information in this form and that all your questions have been answered. 
1. I was informed that the objectives of this study are determining the effect of group counseling based on problem-solving approach on sexual function of women after mastectomy and determining the effect of group counseling based on problem-solving approach on sexual satisfaction of women after mastectomy, and that this intervention might be useful and effective for me.

2. I was informed that my participation in this research is completely voluntary and I am not forced to participate in this research. I was assured that I would not be deprived of routine diagnostic and therapeutic care if I refused to participate in the study. Also, my therapeutic relationship with medical centers and medical staff will not deteriorate and the routine treatment methods will continue for me.

3. I was informed that even after agreeing to participate in the research, I could leave the research whenever I wanted. My withdrawal will not deprive me of the routine care, diagnostic, and treatment services and will not require a fine or compensation.

4. My cooperation in this research is voluntary after being fully informed and through filling out questionnaires and participating in group counseling sessions.

5. I was informed that using the benefits of this research include free to access to counseling sessions and free access to educational materials in the field of sexual health.

6. I was informed that this study has no side effects or harm.

7. I was informed that if my participation should ensue any severe complications, the research method will be discontinued and the research executor will be responsible for compensating the harm and cost.

8. I was informed that those involved in this research will keep all information about me confidential and are only allowed to publish the general and group results of this research without mentioning my name or details.

9. I was informed that I would not be responsible for any of the costs of conducting research interventions.

10. I was informed that I will be notified if there is a change in the research process that will affect my health and my decision to continue participating in the project.

11. I was informed that some situations such as absence for 2 sessions may end my participation in the study.

12. I was informed that the researchers will inform me of the results of this project after the completion of the research process.

13. I was informed that the Research Ethics Committee at Shahid Sadoughi Medical School, Yazd, Iran (Tel number: 0098353820253) can access my information to monitor if my rights are observed.

14. I was informed that if I have any problems or objections to those involved or the research process, I can contact the Research Ethics Committee of the Medical School at Shahid Sadoughi Medical School, Yazd, Iran (Tel number: 0353820253) and inform them of my problem.

15. Dr. Mahshid Bokaei was introduced to me as the executor of the project to answer my questions and I was told to share any problems, questions, or complications regarding participating in this research with her and ask for advice. 
Mobile phone: 00989131538064; Landline: 00983538241751; Email: mah_bokaie@yahoo.com

Address: School of Nursing and Midwifery, across from Infertility Institute, Timsar Fallahi St., Safaieh, Yazd, Iran.

In view of the above and gaining sufficient information, I daughter of with ID number and national code hereby declare my informed and voluntary consent to participate in the above research project.

Address and contact number:

Participant's signature and fingerprint: Date:

I, Ommolbanin Firoozabadi, consider myself obliged to fulfill the obligations related to the executor in the above provisions, and I undertake to work to ensure the provision of the rights and safety of the participant in the research.

Seal and signature of the researcher

This form of information and informed consent is set in two copies and one copy will be given to the participant and the other copy to the executor after signing.

\section{Consent for publication}

Not applicable.

\section{Availability of data and materials}

The datasets used and analyzed during the present study are available from the corresponding author on reasonable request.

\section{Competing interests}

The authors declare that they have no competing interests.

\section{Funding}

Not applicable

\section{Authors 'contributions}

O.F.: Conception and design, provision of study materials of patients, collection and assembly of data, data analysis and interpretation, article writing, review and editing. M.B. and A.J.: Conception and design, review and editing. All three authors read and approved the final manuscript. 


\section{Acknowledgements}

This paper is extracted from Counseling in Midwifery Master's Degree Thesis approved by Shahid Sadoughi University of Medical Sciences of Yazd. We would like to express our appreciations to all personnel of Tehran Breast Cancer Institute for their cooperation in execution of this research and the personnel of Shahid Sadoughi University of Medical Sciences.

\section{References}

1. HERAVI KM, Pourdehghan M, JADID MM, FOROUTAN SK, Aein F. Effect of group counseling on sexual health of patients with breast cancer. 2006.

2. Organization WH. Breast cancer. nd http://www. who. int/cancer/prevention/diagnosisscreening/breast-cancer/en. Accessed; 2018.

3. KOLAH DS, SAJADI A, Radmard AR, KHADEMI H. Five common cancers in Iran. 2010.

4. shayan a, KHALILI A, rahnavardi $m$, masoumi sz. The relationship between sexual function and mental health of women with breast cancer. 2016.

5. Black JM, Hawks JH. Medical-surgical nursing: Elsevier Saunders; 2005.

6. Esfandiari Dolabi Z, Joulaei A, Asli Azad M. Comparison of marital satisfaction and general health among breast cancer patients with breast evacuation, breast keeping and cancer free women in Tehran. IJRR. 2015;1(4):39-48.

7. Novak E. Berek \& Novak's gynecology: Lippincott Williams \& Wilkins; 2007.

8. Rosenhan DL, Seligman ME. Abnormal psychology: WW Norton \& Co; 1995.

9. Gibbs AA, Dazzan P, Morgan KD, Naudts KH, Morgan C, Hutchinson G, et al. Sexually dimorphic changes in the amygdala in relation to delusional beliefs in first episode psychosis. Journal of psychiatric research. 2008;42(11):913-9.

10. Fahami F, Savabi M, Mohamadirizi S. Relationship of sexual dysfunction and its associated factors in women with genital and breast cancers. Iranian Journal of Nursing and Midwifery Research. 2015;20(4):516.

11. Panjari M, Bell RJ, Davis SR. Sexual function after breast cancer. The journal of sexual medicine. 2011;8(1):294-302.

12. Wilmoth MC, Sanders LD, editors. Accept me for myself: African American women's issues after breast cancer. Oncology nursing forum; 2001.

13. Mofid V, Ahmadi A, Etemadi O. The comparison of Cognitive-Behavioral counseling and SolutionOriented counseling on women's sexual satisfaction in Isfahan. 2014.

14. Ramezani T. Requiring depression counseling for women with breast cancer. Andishe va Raftar. 2001;6(8):70-7.

15. Navabinezhad S. Guidance and group counseling. Tehran: Organization of Study and Codification the Social Sciences Books. 2010. 
16. Gellis ZD, Kenaley B. Problem-solving therapy for depression in adults: a systematic review. Research on Social Work Practice. 2008;18(2):117-31.

17. Mynors-Wallis L. Problem-solving treatment in general psychiatric practice. Advances in psychiatric treatment. 2001;7(6):417-25.

18. Cannon B, Mulroy R, Otto MW, Rosenbaum JF, Fava M, Nierenberg AA. Dysfunctional attitudes and poor problem solving skills predict hopelessness in major depression. Journal of affective disorders. 1999;55(1):45-9.

19. Gaskell L, Beaton S. Developing clinical competency: Experiences and perceptions of Advanced Midwifery Practitioners in training. Nurse education in practice. 2015;15(4):265-70.

20. Khosravi Z. Sexual function in women after vaginal delivery and cesarean section compared to health centers of Mashhad. Iran: Mashhad University of Medical Sciences. 2000.

21. Pakgohar M, Vizheh M, Babaee G, Ramezanzadeh F, Abedininia N. Effect of counseling on sexual satisfaction among infertile women referred to Tehran fertility center. Journal of hayat. 2008;14(1):21-30.

22. Karakoyun-Celik O, Gorken I, Sahin S, Orcin E, Alanyali H, Kinay M. Depression and anxiety levels in woman under follow-up for breast cancer: relationship to coping with cancer and quality of life. Medical Oncology. 2010;27(1):108-13.

23. Rostamkhani F, Ozgoli G, MERGHATI KE, Jafari F, ALAVI MH. Effectiveness of the PLISSIT-based Counseling on sexual function of women. 2012.

24. Karimoi H, Pourdehghan M, Faghihzadeh S, Montazeri A, Milani J. The effects of group counseling on symptom scales of life quality in patients with breast cancer treated by chemotherapy. 2006.

25. Kedde H, Van de Wiel H, Schultz WW, Wijsen C. Subjective sexual well-being and sexual behavior in young women with breast cancer. Supportive Care in Cancer. 2013;21(7):1993-2005.

26. Chen C-P, Huang K-G, Wan G-H, Tu L-Y, Lee J-T. Sexual satisfaction and related factors in women previously treated for gynecological cancer. Hu Li Za Zhi. 2013;60(2):61.

27. Reese JB, Zimmaro LA, Lepore SJ, Sorice KA, Handorf E, Daly MB, et al. Evaluating a couple-based intervention addressing sexual concerns for breast cancer survivors: study protocol for a randomized controlled trial. Trials. 2020;21(1):173.

28. Avis NE, Crawford S, Manuel J. Psychosocial problems among younger women with breast cancer. Psycho-Oncology: Journal of the Psychological, Social and Behavioral Dimensions of Cancer. 2004;13(5):295-308.

29. Wilmoth MC, Coleman EA, Smith SC, Davis C, editors. Fatigue, weight gain, and altered sexuality in patients with breast cancer: exploration of a symptom cluster. Oncology nursing forum; 2004 : ONCOLOGY NURSING SOCIETY 125 ENTERPRISE DR, PITTSBURGH, PA 15275 USA.

30. Fobair P, Stewart SL, Chang S, D'Onofrio C, Banks PJ, Bloom JR. Body image and sexual problems in young women with breast cancer. Psycho-Oncology: Journal of the Psychological, Social and Behavioral Dimensions of Cancer. 2006;15(7):579-94. 
31. Molavi A, Hekmat K, Afshari P, Hoseini M. Evaluation of couples' sexual function and satisfaction after mastectomy. The Iranian Journal of Obstetrics, Gynecology and Infertility. 2015;17(134):17-24.

32. Phipps WJ, Monahan FD, Sands J, Marek J, Neighbors M. Medical-surgical nursing: Health and illness perspectives: Mosby St. Louis; 2003. 